T. J. Hilbish $\cdot$ A. Mullinax $\cdot$ S. I. Dolven $\cdot$ A. Meyer

R. K. Koehn · P. D. Rawson

\title{
Origin of the antitropical distribution pattern in marine mussels (Mytilus spp.): routes and timing of transequatorial migration
}

Received: 8 December 1998 / Accepted: 8 November 1999

\begin{abstract}
Many marine species, including mussels in the Mytilus edulis species group (i.e. M. edulis L., M. galloprovincialis Lamarck, and M. trossulus Gould), have an antitropical distribution pattern, with closely related taxa occurring in high latitudes of the northern and southern hemispheres but being absent from the tropics. We tested four hypotheses to explain the timing and route of transequatorial migration by species with antitropical distributions. These hypotheses yield different predictions for the phylogenetic relationship of southern hemisphere taxa relative to their northern counter-parts. The three Mytilus species were used to test these hypotheses since they exhibit a typical antitropical distribution and representative taxa occur in both the Pacific and Atlantic. Two types of mtDNA lineages were found among populations of mussels collected from the southern hemisphere between 1988 and 1996; over 90\% of the mtDNA lineages formed a distinct subclade which, on average, had $1.4 \%$ divergence from haplotypes found exclusively in northern Atlantic populations of M. galloprovincialis. These data indicate that southern
\end{abstract}

Communicated by J.P. Grassle, New Brunswick

T.J. Hilbish $(\square)$

Department of Biological Sciences,

University of South Carolina, Columbia,

South Carolina 29208, USA

e-mail: hilbish@biol.sc.edu

A. Mullinax $\cdot$ S.I. Dolven

Medical University of South Carolina, Charleston,

South Carolina 29425, USA

A. Meyer

Department of Biology, University of Konstanz,

D-78457 Konstanz, Germany

R.K. Koehn

Vice President for Research, 201 S President's Circle,

Room 210, University of Utah, Salt Lake City,

Utah 84112-9011, USA

P.D. Rawson

School of Marine Sciences, University of Maine, Orono, Maine 04469, USA hemisphere mussels arose from a migration event from the northern hemisphere during the Pleistocene via an Atlantic route. The remainder of the southern hemisphere lineages $(<10 \%)$ were very closely related to mtDNA haplotypes found in both $M$. edulis and $M$. galloprovincialis in the northern hemisphere, suggesting a second, more recent migration to the southern hemisphere. There was no evidence that southern hemisphere mussels arose from Pacific populations of mussels.

\section{Introduction}

Many marine taxa have distribution patterns in which closely related species occupy the temperate zones of both the northern and southern hemispheres but are absent from the intervening tropical regions. Ekman (1953) called this a "bipolar" pattern of distribution, whereas Hubbs (1952) termed it "antitropical", to emphasize the absence of these taxa in the tropics. Antitropical distributions are very common and include taxa ranging from algae to seals (Ekman 1953; Raven 1963; Pielou 1979). For example Santelices (1980) estimated that over $18 \%$ of marine flora have antitropical distribution patterns.

The geographical and historical origins of antitropical distribution patterns are unclear. Antitropical distributions may arise through vicariance processes where a taxon was formerly distributed across the tropics or, alternatively, through migration across the tropics. In an extensive review of antitropical biotas Lindberg (1991) rejected the vicariance model based on the fossil records of many taxa, which show that the ancestral species originated in higher latitudes but not in the equatorial region. Also, the necessary geologic events for vicariance hypotheses have not occurred within the period in which the antitropic distributions of most of the near-shore taxa arose (Lindberg 1991).

Transequatorial migration is the most likely explanation for the origin of antitropic distributions of most 
near-shore marine taxa. Lindberg (1991) concluded that at least two major periods of biotic exchange have occurred. The larger of the two occurred during the late Pliocene, about 3.1 million years ago (mya), and coincided with the formation of the Isthmus of Panama. This exchange was asymmetric with about $90 \%$ of the species migrating from north to south. A smaller exchange occurred during the Pleistocene and was much more symmetrical (Lindberg 1991).

At least four hypotheses can be erected to account for the origin and timing of antitropical distributions.

Hypothesis 1: the Pliocene-Pacific hypothesis. The emergence of the Isthmus of Panama and the closure of the Panamic portal about 3.1 mya caused rapid changes in near-shore temperature and current patterns (Keigwin 1982; Weaver 1990) and occurred just before the larger of the two biotic exchanges between the temperate regions of the eastern Pacific (Lindberg 1991). Therefore the antitropical distribution patterns in any given group of marine species may arise during this time through transequatorial exchange along an eastern Pacific route. Since the Pliocene exchange was larger than subsequent transequatorial exchanges that occurred in the eastern Pacific (Lindberg 1991) it is reasonable to assume that the antitropic distribution of any particular group arose during the Pliocene. Also, Lindberg (1991) indicates the Pliocene exchange was asymmetrical so it is also likely that the southern hemisphere was invaded by species from the northern Pacific.

Hypothesis 2: the Pleistocene-Pacific hypothesis. A second pulse of transequatorial exchange occurred in the Pleistocene and was coincident with the onset of glacial cooling (Lindberg 1991). During glacial maxima polar fauna expanded towards the equator, but there is little evidence for contraction of the tropics (Moore et al. 1981). Lindberg (1991) argued that glacial cooling resulted in increased upwelling activity along the margin of the eastern Pacific and that Pleistocene exchanges across the equator may have occurred via a succession cold-water refugia.

Hypothesis 3: the Pleistocene-Atlantic hypothesis. Transequatorial migrations may have occurred in the Pleistocene during periods of glacial cooling but through the Atlantic Ocean. Vermeij (1992) has argued that this route is unlikely because the tropical zone in the Atlantic remained relatively broad throughout the Pleistocene, and temperate faunas of South Africa contain very few species with origins in the northern Pacific, even though many species from the North Pacific colonized the northern Atlantic during a trans-arctic migration in the middle Pliocene (Vermeij 1991). Vermeij (1992) concluded that the temperate regions of the Atlantic have been isolated from the Middle Pliocene ( 3.5 mya) to the present.

Hypothesis 4: introductions via human activities. Human shipping activities have led to the introduction of many marine species (Carlton 1989; Carlton and Geller 1993). It is possible that human activity has spread many northern hemisphere temperate species to the southern hemisphere, and vice versa, generating some relatively recent antitropical distributions.

We have tested these four hypotheses for the origin of the antitropical distribution of the mussel species in the Mytilus edulis complex. This group exhibits a typical antitropical distribution (see Fig. 1). Three species occur in the northern hemisphere; M. trossulus in the Pacific, the northwestern Atlantic, and the Baltic Sea, M. edulis in the Atlantic, and M. galloprovincialis in the Mediterranean, and along the Atlantic coasts of southern Europe and north Africa (Gosling 1984, 1992; Koehn 1991; McDonald et al. 1991; Suchanek et al. 1997). M. galloprovincialis has also been introduced to the Sea of Japan, Southern California, and Puget Sound (McDonald et al. 1991; Gosling 1992; Suchanek et al. 1997). In the southern hemisphere, mussels that are closely related to those in the M.edulis complex of the northern hemisphere occur along the temperate Pacific and Atlantic coasts of South America, the Kerguelen Islands (McDonald et al. 1991), South Africa, Australia, Tasmania, and New Zealand (Grant and Cherry 1985; Beaumont et al. 1989; McDonald et al. 1991).

Previous studies have determined the phylogenetic relationships among the northern hemisphere Mytilus spp., providing a background for testing the four hypotheses for the origin of the southern hemisphere mussels. Northern hemisphere M. edulis and M. galloprovincialis are sister taxa, probably began to diverge about 2 mya, and have exchanged genes through hybridization (Rawson and Hilbish 1995b, 1998; Quesada et al. 1998). M. trossulus is more distantly related and has probably been diverging from the other two species for about 3.5 million years (Vermeij 1991; Rawson and Hilbish 1995b, 1998).

The four hypotheses for the origin of southern hemisphere mussels make distinct predictions about the phylogenetic relationship between mussels from the southern hemisphere and those from the northern hemisphere. The Pliocene-Pacific hypothesis predicts that southern hemisphere species of Mytilus will be most closely related to Pacific populations of M. trossulus and that this relationship is relatively old ( $\sim 3$ mya). The Pleistocene-Pacific hypothesis predicts the same topology but that the divergence between Pacific populations of $M$. trossulus and southern hemisphere mussels is more recent ( $\sim 1$ to 2 mya). The Atlantic-Pleistocene hypothesis predicts that southern hemisphere mussels will be closely related to species endemic to the Atlantic (M. galloprovincialis or M. edulis). The human introduction hypothesis predicts that southern hemisphere mussels will be indistinguishable from northern hemisphere species. Finally, phylogenetic information can also be used to test the direction of the transequatorial exchanges establishing the antitropical distribution of Mytilus spp. If the exchange was from north to south then all southern hemisphere lineages are predicted to diverge after the common ancestor of the northern hemisphere species. If the exchange was south to north then the reverse is predicted; northern hemisphere lin- 
eages will have originated after the common ancestor of southern hemisphere lineages.

We tested these predictions using two approaches. First, we surveyed restriction site variation in the mitochondrial 16S rRNA gene to determine whether southern hemisphere species exhibit patterns of variation similar to those of northern hemisphere species (e.g. Rawson and Hilbish 1995a). Second, to test the four hypotheses for the origins of the antitropical distribution of Mytilus spp. we sequenced a portion of the 16S rRNA mitochondrial gene of mussels collected from the southern hemisphere and compared these data with mtDNA sequences previously obtained from the three northern hemisphere species.

\section{Materials and methods}

Mussels from the southern hemisphere were collected between 1988 and 1996 from Chiloe Island, Chile (Ci) $\left(42^{\circ} \mathrm{S} ; 74^{\circ} \mathrm{W}\right)$, Punta Arenas, Chile $(\mathrm{Pa})\left(53^{\circ} \mathrm{S} ; 71^{\circ} \mathrm{W}\right)$, the Falkland Islands $(\mathrm{Fa})\left(52^{\circ} \mathrm{S}\right.$; $\left.58^{\circ} \mathrm{W}\right)$, the Kerguelen Islands (Ki) $\left(49^{\circ} \mathrm{S} ; 70^{\circ} \mathrm{E}\right)$, Perth, Australia (Pe) $\left(32^{\circ} \mathrm{S} ; 116^{\circ} \mathrm{E}\right)$, Albany, Australia (Al) $\left(34.5^{\circ} \mathrm{S} ; 118^{\circ} \mathrm{E}\right)$, and Port Philip Bay, Australia $(\mathrm{Pp})\left(38^{\circ} \mathrm{S} ; 145^{\circ} \mathrm{E}\right)$, Hobart, Tasmania, Australia (Ta) $\left(43^{\circ} \mathrm{S} ; 147^{\circ} \mathrm{E}\right)$, Otago, South Island, New Zealand (Ot) $\left(46^{\circ} \mathrm{S} ; 170^{\circ} \mathrm{E}\right)$, and Wellington, North Island, New Zealand (We) $\left(41^{\circ} \mathrm{S} ; 174^{\circ} \mathrm{E}\right)$ (Fig. 1). Tissue samples were preserved in 70 to $90 \%$ ethanol or freeze-dried prior to shipping.
A $50 \mathrm{mg}$ subsample of each tissue was digested for $3 \mathrm{~h}$ at $55^{\circ} \mathrm{C}$ in $300 \mu \mathrm{l}$ lysis buffer $(50 \mathrm{~m} M$ Tris- $\mathrm{HCl}, \mathrm{pH} 8.0 ; 1 \%$ SDS; $25 \mathrm{mM}$ EDTA) with $100 \mu \mathrm{g}$ of proteinase $\mathrm{K}$. Total nucleic acids were isolated by extracting the completely digested tissue once with phenol/chloroform $(1: 1)$ followed by precipitation with $95 \%$ ethanol. The DNA was then washed in $70 \%$ ethanol, air-dried, and resuspended in $100 \mu \mathrm{l}$ of TE.

\section{RFLP analysis}

We amplified 527 nucleotides of the maternally inherited mitochondrial 16S rRNA gene by the polymerase chain reaction (PCR) using primers described by Rawson and Hilbish (1995a, b) which are specific for the female mtDNA $16 \mathrm{~S}$ gene. Each PCR reaction was conducted in a total volume of $12 \mu \mathrm{l}$ using an amplification cocktail containing $1.25 \mu \mathrm{l} 10 \times$ PCR buffer, $0.75 \mu \mathrm{l} 25 \mathrm{mM} \mathrm{MgCl}$, $0.25 \mu 10 \mathrm{~m} M$ DNPTs, $10 \mu \mathrm{DDH}_{2} \mathrm{O}, 0.10$ Taq DNA polymerase

Fig. 1 Mytilus spp. Antitropical global distribution of blue mussels. Approximate distributions of mussels were compiled from various sources, including Koehn (1991), McDonald et al. (1991), Gosling (1992), Suchanek et al. (1997). Hatched areas (denoted "mixture") indicate regions of sympatry and hybridization between species pairs. Dark stipling indicates the distribution of Mytilus spp. in the southern hemisphere. Sampling sites in the southern hemisphere are identified in "Materials and methods". Northern hemisphere sites sampled for the DNA sequence analysis are also given (Or Newport, Oregon, USA; $C a$ San Diego, California, USA; De Lewes, Delaware, USA; $W b$ Whitsand Bay, United Kingdom; Ex Exmouth, United Kingdom; $S p$ Galicia, Spain; Fr Sete, France; It Venice, Italy; Ba Aland Island, Finland)

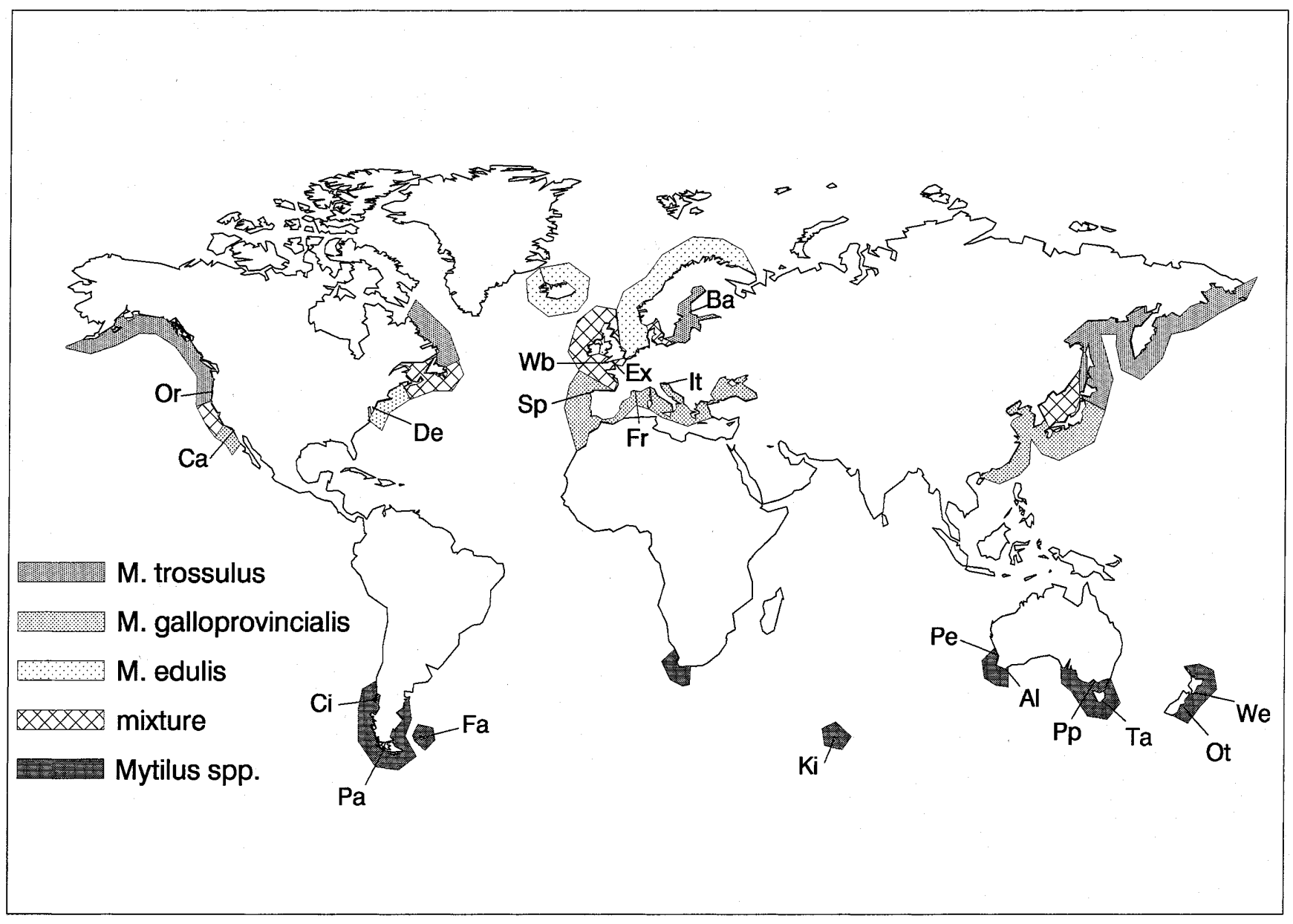


(Promega), and $0.125 \mu \mathrm{l}$ of each of the female-specific PCR primers JH-48 and PR-16 (Rawson and Hilbish 1995a). One microliter of each DNA sample was used for amplification. Positive controls containing DNA samples of known haplotype and blanks without DNA were simultaneously amplified in an identical fashion.

The sample tubes were then placed into an MJ Research Thermal Cycler where they were denatured initially for $3 \mathrm{~min}$ at $94{ }^{\circ} \mathrm{C}$, and then incubated for 30 cycles at $94{ }^{\circ} \mathrm{C}$ for $20 \mathrm{~s}, 51{ }^{\circ} \mathrm{C}$ for $20 \mathrm{~s}$, and $72{ }^{\circ} \mathrm{C}$ for $45 \mathrm{~s}$. The samples were then removed and electrophoresed on a $1 \%$ agarose gel. Successfully amplified DNA samples were then digested with the restriction enzymes EcoRV and SpeI as described by Rawson and Hilbish (1995a). This assay yields three restriction patterns in members of the Mytilus spp. complex (Rawson and Hilbish 1995a). M. trossulus is fixed for a female mtDNA haplotype (designated B by Rawson and Hilbish 1995b), $M$. edulis is fixed for a second pattern (haplotype A), and pure populations of $M$. galloprovincialis have about equal frequencies of haplotype A and a third restriction pattern (haplotype D). Southern hemisphere mussels were classified into one of these three haplotypes based on their mtDNA restriction patterns; no new restriction patterns were observed among southern hemisphere mussels. Not all sample locations were included in the analysis of restriction site polymorphisms.

\section{Sequence analysis}

After the RFLP analysis was completed, individuals representing different mtDNA haplotypes were chosen for DNA sequence analysis. Rawson and Hilbish (1998) previously reported $28 \mathrm{mt} 16 \mathrm{~S}$ rRNA sequences for female mitochondrial lineages for northern hemisphere mussels, including allopatric populations of Mytilus edulis, M. galloprovincialis, and $M$. trossulus. These sequences are available from GenBank (Accession Numbers U22864 to U22886). In the present study, we generated an additional 40 sequences from southern hemisphere mussels either by cloning PCR products with subsequent plasmid sequencing, or by direct sequencing of PCR products.

For plasmid sequencing, PCR products (16S female mtDNA) were re-amplified and gel purified using the Gene Clean II Kit (Bio 101, San Diego, California). The purified product was then resuspended in $12 \mu \mathrm{H}_{2} \mathrm{O}$. The resulting products were gel purified using the Gene Clean II Kit (Bio101) and ligated into the vector pGEM-T using the manufacturer's protocol (Promega, Madison, Wisconsin). The resulting plasmids were used to transform competent Escherichia coli (JM109) provided with the vector, and positive colonies were selected using the manufacturer's protocol. The presence of inserts in positive colonies was checked using vector-specific primers T7 and Sp6 and the PCR method of Palumbi and Baker (1994). The positive colony PCR products were assayed by digestion with the restriction enzymes EcoRV and SpeI to ensure that the colonies contained maternal mtDNA inserts. With this combination of enzymes female haplotypes are cut into two or more bands resolvable on $1.5 \%$ agarose gels, while male products remain undigested.

Clones were isolated and sequenced in one direction using a Sequenase kit, the standard kit protocol, and the vector-sequencing primers T7 and Sp6 (Amersham, Cleveland, Ohio). In addition, sequences for both female mtDNA lineages from two Mytilus californianus individuals, one from San Diego and one from Bodega Bay (California, USA), were obtained using these same methods.

For direct sequencing, double-stranded amplifications were performed using $25-\mu \mathrm{l}$ volumes containing $67 \mathrm{~m} M$ Tris (pH 8.8), $6.7 \mathrm{~m} M \mathrm{MgCl}_{2}, 16.6 \mathrm{~m} M\left(\mathrm{NH}_{4}\right)_{2} \mathrm{SO}_{4}, 10 \mathrm{~m} M$ 2-mercaptoethanol, $1 \mathrm{~m} M$ of each dNTP, $1 \mu M$ of each primer, 10 to $1000 \mathrm{ng}$ genomic DNA, and 0.5 units of Taq polymerase (Cetus Corp.). Primers used were 16Sar-L (5'-CGCCTGTTTATCAAAAACAT-3') and 16SbrH (5'-CCGGTCTGAACTCAGATCACGT-3') (Palumbi et al. $1991)$ to obtain an amplification product of $\sim 600 \mathrm{bp}$. Gel purification $(2.5 \%$ NuSieve-Agarose, in TAE buffer) of the doublestranded product was followed by generation of single-stranded DNA for both strands for direct sequencing, using asymmetric
PCR (Gyllensten and Erlich 1988). Single-stranded DNA was concentrated and desalted in spin columns (Millipore: UltrafreeMC 30,000), and both strands were sequenced by dideoxy methods using a commercial kit (Sequenase, United States Biochemical). Direct sequencing potentially yielded both male and female mitochondrial lineages; only female lineages (as determined by comparing the sequence with those reported by Rawson and Hilbish 1995b) were used in this study.

The sequences generated in this study were aligned with those reported by Rawson and Hilbish (1998) using the ESEE sequence editor (Cabot and Beckenbach 1989). The alignment among all northern and southern blue mussel sequences was unambiguous. To align the Mytilus californianus sequences we used the BESTFIT program in the University of Wisconsin's GCG package (Devereux et al. 1984). Genetic distances between pairs of sequences were estimated using the Kimura two-parameter model which allows for unequal transition and transversion frequencies and a neighborjoining phylogeny estimated from the resulting distance matrix using PAUP*4.0 (Swofford 1998). The use of alternative substitution models had no effect on the topology of the neighbor-joining phylogeny (data not shown). We used a bootstrap test (1000 iterations) to test for the probability of internal branch lengths being greater than zero).

Estimation of a maximum parsimony phylogeny was complicated by the fact that of the 496 variable base pairs in our data set, only 30 were parsimoniously informative. Thus, a heuristic search with simple sequence addition and nearest neighbor interchange swapping procedure in PAUP* generated over 100,000 trees, each 113 steps in length. To reduce the search time, we saved the first 100 trees, 113 steps in length, generated from a heuristic search with random sequence addition. Each of the 100 trees was then input into a tree bisection-reconnection swapping procedure to search for optimal trees. The random sequence addition was itself repeated 100 times generating a total of 10,000 trees of length 113 steps from which a majority-rule consensus phylogeny was estimated. A bootstrap test with 1000 iterations and employing the FASTSTEP option in PAUP* was used to place a confidence estimate on each of the groupings within this maximum-parsimony phylogeny. In addition, we used the reverse constraints approach to estimate decay indices (Bremmer 1994) for each of the internal nodes in the maximum-parsimony phylogeny. Due to the size and complexity of the data set, no branch swapping was performed while estimating the decay indices. Instead, for each constraint, 1000 replicate trees were constructed by random sequence addition, and the length of the shortest tree among these replicates, minus the length of the maximum-parsimony tree, provided the support index for a given node.

A maximum-likelihood phylogeny was also estimated using PAUP*. A comparison of several substitution models indicated that the simplest model that best fit the data was one with two substitution types, the transition to transversion ratio estimated from the data and a molecular clock enforced (data not shown). A bootstrap analysis with 100 iterations was used to test whether internal branch lengths in the maximum-likelihood phylogeny were $>0$.

\section{Results}

Frequencies of female haplotypes in Mytilus spp. from the southern hemisphere are given in Table 1 along with previously determined haplotype frequencies from the northern hemisphere. With the exception of the Kerguelen Islands, all southern hemisphere mussels had very high frequencies of the D female 16S mtDNA haplotype. One individual with an A haplotype was observed from Otago, New Zealand. In the northern hemisphere, the D haplotype is unique to $M$. galloprovincialis and mussel populations with hybrids of this species (Rawson and 
Table 1 Mytilus spp. Frequency (\%) of female 16S rRNA RFLP haplotypes in mussel populations from the northern and southern hemisphere. Northern hemisphere data (Rawson and Hilbish 1998) are haplotype frequencies in representative populations of Mytilus edulis, M. trossulus, and M. galloprovincialis ( $n$ sample size at each location)

\begin{tabular}{|c|c|c|c|c|}
\hline \multirow[t]{2}{*}{ Location } & \multirow[t]{2}{*}{$n$} & \multicolumn{3}{|c|}{ Haplotype } \\
\hline & & A & $\mathrm{B}$ & $\mathrm{D}$ \\
\hline \multicolumn{5}{|l|}{ Northern hemisphere } \\
\hline $\begin{array}{l}\text { Cape Ann, Massachusetts, USA } \\
\text { Mytilus edulis }\end{array}$ & 36 & 100 & 0 & 0 \\
\hline $\begin{array}{l}\text { Newport, Oregon, USA } \\
\text { Mytilus trossulus }\end{array}$ & 54 & 0 & 100 & 0 \\
\hline $\begin{array}{l}\text { Portofino, Italy } \\
\quad \text { Mytilus galloprovincialis }\end{array}$ & 46 & 60 & 0 & 40 \\
\hline \multicolumn{5}{|l|}{ Southern hemisphere } \\
\hline Castro, Chile & 35 & 0 & 0 & 100 \\
\hline Kerguelen & 5 & 100 & 0 & 0 \\
\hline Port Phillip Bay, Australia & 13 & 0 & 0 & 100 \\
\hline Hobart, Tasmania, Australia & 17 & 0 & 0 & 100 \\
\hline Wellington and Otago, New Zealand & 25 & 4 & 0 & 96 \\
\hline
\end{tabular}

Hilbish 1998). Only five individuals were successfully assayed from the Kerguelen Islands and all of them had haplotype A.

Forty southern hemisphere mussels were successfully sequenced. There were 20 unique southern hemisphere sequences (GenBank Accession Numbers AF179443 to AF179462) and none were identical with sequences observed in the northern hemisphere. The results from all three phylogeny estimates were quite similar. They indicated that there were two types of southern hemisphere female 16S mtDNA sequences (Figs. 2, 3, 4). The first type clustered together into a single clade whose closest northern hemisphere relative is the D clade of haplotypes found in Mytilus galloprovincialis. This clade includes sequences from all southern hemisphere locations (Table 2), except the Kerguelen Islands. Indeed, haplotype SH2 (Table 2) was found in Chile, the Falklands, Tasmania, and New Zealand. Although all three phylogenetic estimates found this clade, the bootstrap analysis did not strongly support the branch leading to this clade in the neighbor-joining analysis. The parsimony and maximum-likelihood analysis, however, both found that the northern hemisphere D clade is significantly distinguished from southern hemisphere D haplotypes. This southern hemisphere clade is, on average, $1.4 \%$ divergent from the next closest $\mathrm{D}$ clade of M. galloprovincialis.

We rearranged the maximum-likelihood phylogeny so that the closest relative of this southern hemisphere clade was the B clade found in Mytilus trossulus. We used the DNAMLK algorithm in Phylip 3.5c to estimate the likelihood of the rearranged phylogeny which was compared to the likelihood of the original phylogeny. The rearranged phylogeny, which forces the southern hemisphere clade to be a sister group with $M$. trossulus, was significantly less likely $(P<0.05)$ than the original phylogeny.

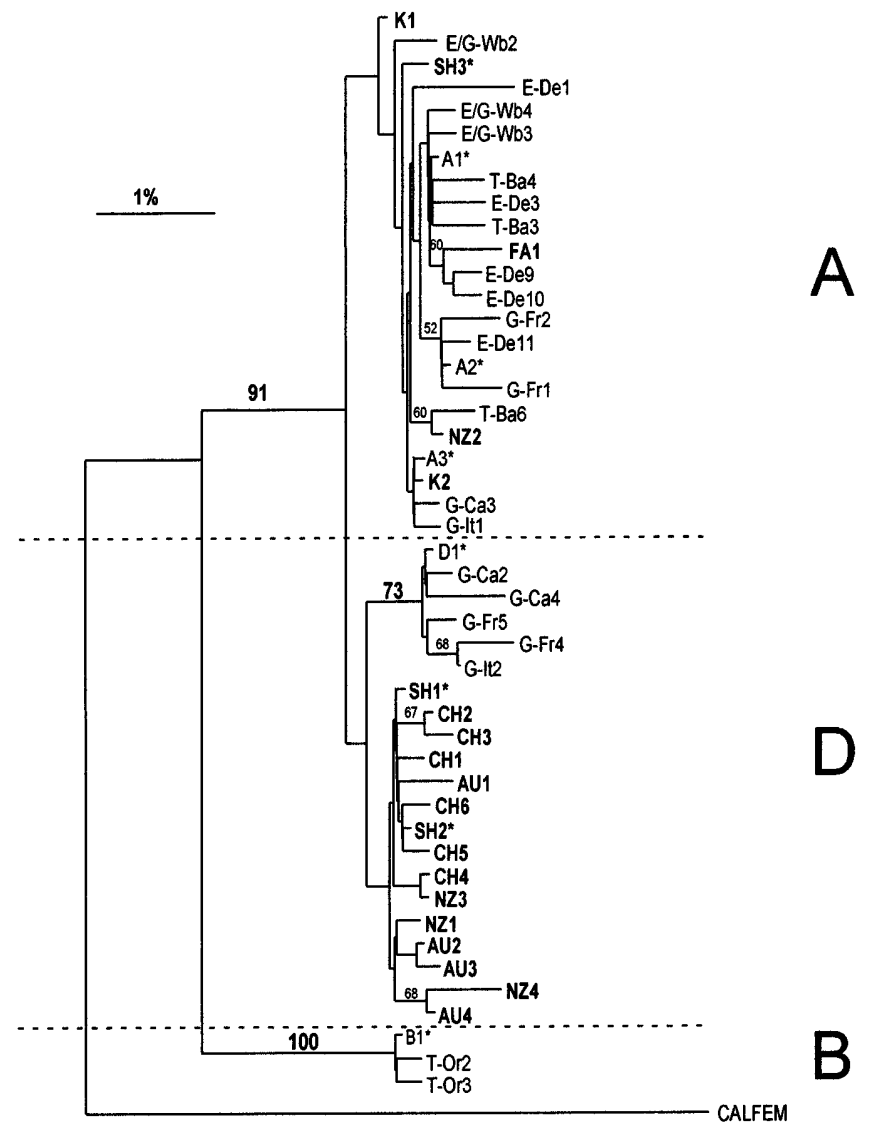

Fig. 2 Mytilus spp. Neighbor-joining phylogeny for the Mytilus mt 16S rRNA maternal mitochondrial lineage sequences from northern and southern hemisphere populations. Northern hemisphere sequences have previously been reported (Rawson and Hilbish 1998). These sequences are labeled as in Rawson and Hilbish (1998) with EDe for M. edulis mussels from Lewes, Delaware, USA (De); G-Ca, GFr, G-It, or G-Sp indicating M. galloprovincialis mussels from San Diego, California, USA $(\mathrm{Ca})$; Sete, France $(\mathrm{Fr})$; Venice, Italy $(\mathrm{It})$; or Galicia, Spain (Sp), respectively (see Fig. 1). T-Or designates sequences obtained from $M$. trossulus mussels sampled from Newport, Oregon, USA $(\mathrm{Or})$. T-Ba indicates putative $M$. trossulus obtained from Aland Island in the Baltic Sea $(B a)$. Sequences for $M$. edulis/ $M$. galloprovincialis hybrid mussels from Whitsand Bay $(W b)$ and Ex River $(E x)$, United Kingdom are indicated by $E / G-W b$ and $E / G-E x$. The three RFLP haplotype patterns $(A, B$, and $D)$ to which the DNA sequences correspond are indicated by dashed lines. Southern hemisphere sequences which have been added to the phylogeny are indicated in bold with $\mathrm{CH}, \mathrm{FA}, \mathrm{K}, \mathrm{AU}$, and $\mathrm{NZ}$ indicating sequences for mussels sampled from Chile (Chiloe Island and Punta Arenas), the Falkland Islands, Kerguelen Island, Australia (Perth, Albany, Port Philip Bay and Hobart, Tasmania), and New Zealand (Wellington and Otago), respectively. In some cases we obtained identical sequences from individuals sampled from different locations; these sequences are indicated as $\mathrm{A} 1^{*}, \mathrm{~A} 2^{*}, \mathrm{~A} 3^{*}, \mathrm{D} 1 *, \mathrm{SH} 1^{*}, \mathrm{SH} 2 *, \mathrm{SH} 3^{*}$ and $\mathrm{B} 1^{*}$. The locations from which these sequences were obtained are given in Table 2 . Bootstrap support values $(\geq 50 \%)$ for branches with length $>0$ are indicated above their respective branches. A female mitochondrial sequence from $M$. californianus (CALFEM) was used to root the tree.

The second type of southern hemisphere female $16 \mathrm{~S}$ rRNA mtDNA sequence is more closely allied with the RFLP haplotype A found in Mytilus edulis and $M$. galloprovincialis in the northern hemisphere. These sequences were found in individuals from the Falkland 


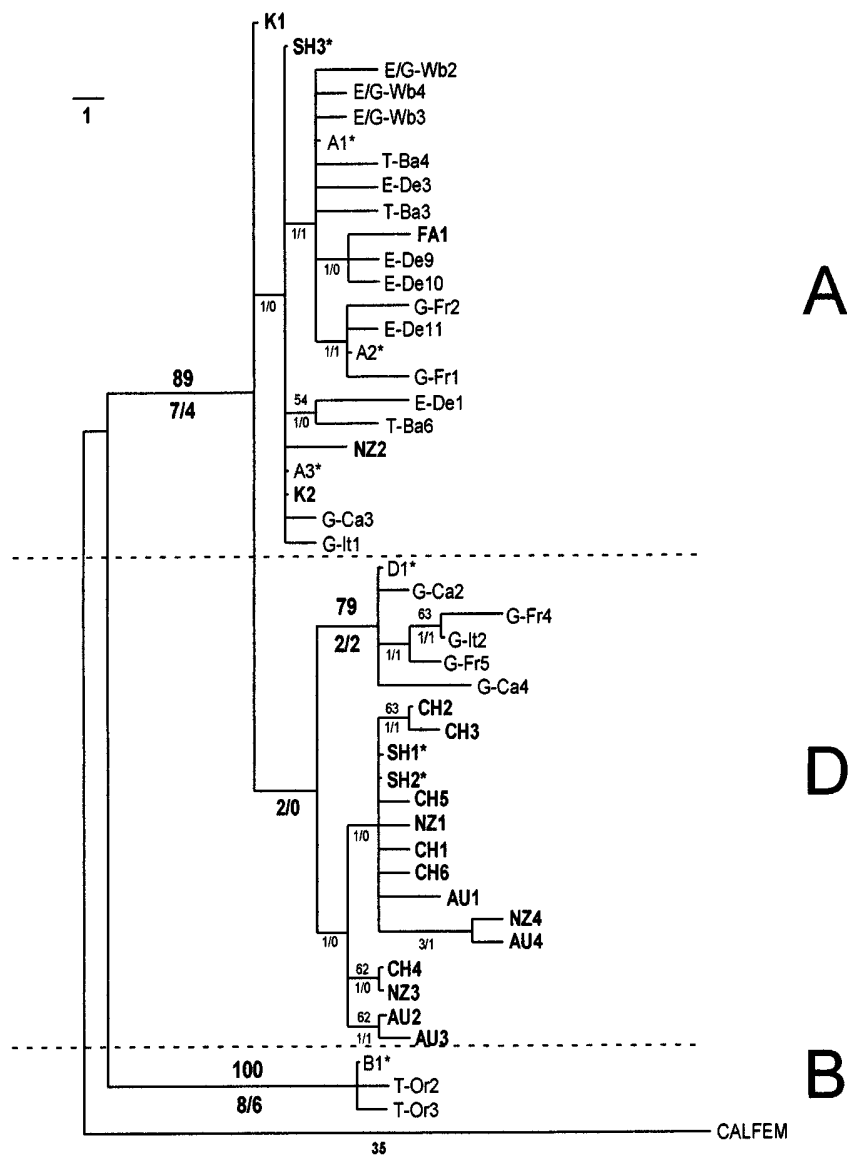

Fig. 3 Mytilus spp. Parsimony phylogeny for female mt16S rRNA sequences sampled from northern and southern hemisphere blue mussels. Sequence designations are the same as in Fig. 2. Groupings present in $>50 \%$ of bootstrap replicates indicated by numbers above a given branch. The number of steps along internal branches followed by the decay index are indicated below each branch

Islands, Kerguelen Island, Perth, Australia, and Wellington, New Zealand. None of these sequences were identical to those found in the northern hemisphere but neither were they very divergent. None of the three phylogenetic analyses suggested that the southern hemisphere A haplotypes form a distinct clade (Figs. 2, 3, 4). On average these sequences are $0.3 \%$ divergent from other A haplotypes found in the northern hemisphere.

\section{Discussion}

Two types of mtDNA lineages were found among populations of mussels from the southern hemisphere. Over $90 \%$ of the southern hemisphere mtDNA lineages formed a subclade within the D restriction haplotype, which is found exclusively in populations of Mytilus galloprovincialis in the northern hemisphere. The remainder of the southern hemisphere lineages were very closely related to the A restriction haplotype, which is found in both M. edulis and M. galloprovincialis in the northern hemisphere. There was no evidence that

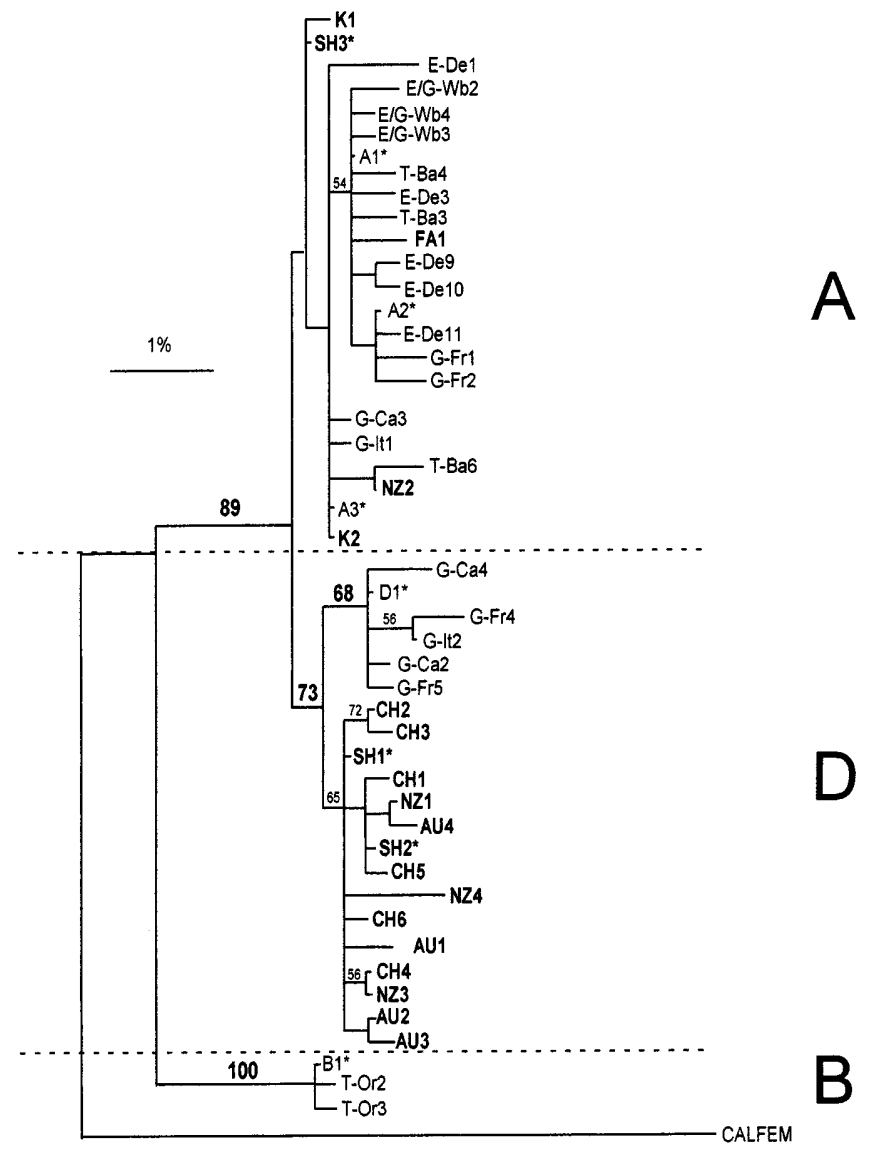

Fig. 4 Mytilus spp. Maximum-likelihood phylogeny for northern and southern hemisphere blue mussel female mt16S rRNA sequences. Sequence designations are the same as in Fig. 2. Bootstrap support values $(\geq 50 \%)$ indicated above their respective branches

southern hemisphere mussels and $M$. trossulus were sister taxa. Indeed, we attempted to rearrange the maximum-likelihood phylogeny so that the closest relative of the southern hemisphere clade was the B clade found in $M$. trossulus but this resulted in a significantly worse phylogenetic estimate. Our results reject both hypotheses proposing routes of transequatorial migration through the Pacific. The greater affinity of southern hemisphere mussel mtDNA lineages with those found in M. edulis

Table 2 Mytilus spp. Identical female mtDNA rRNA sequences observed in multiple individuals. Sample location and haplotype designations follow the schemes described in Fig. 2. The number of individuals observed at a location with the same sequence (if $>1$ ) is given in parentheses

\begin{tabular}{lll}
\hline Haplotype & Hemisphere & Locations \\
\hline A1* & Northern & E-De(4), E/G-Wb, T-Ba(2) \\
A2* & Northern & G-Sp(3), T-Ba, E/G-Wb(4) \\
A3* & Northern & G-Ca(2) \\
B1* & Northern & T-Or(2) \\
D1* & Northern & G-Ca(2), G-Fr, E/G-Ex(2) \\
SH1* & Southern & AU, CH, NZ(3) \\
SH2* & Southern & AU(6), CH(4), FA, NZ(3) \\
SH3* & Southern & AU(4) \\
\hline
\end{tabular}


and M. galloprovincialis indicate an Atlantic route of migration for colonization of the southern hemisphere.

Our results also support the conclusion that the antitropical distribution of Mytilus spp. is the result of transequatorial migration from the northern to the southern hemisphere and not the reverse. All of the mtDNA sequences examined from southern hemisphere populations were nested within the clades found in the two Atlantic northern hemisphere sister-taxa, M. edulis and M. galloprovincialis. M. trossulus is clearly an outgroup compared to the southern hemisphere haplotypes. If the antitropical distribution pattern had formed in this group by migration from the southern to northern hemisphere we would have expected the mtDNA lineages from the southern hemisphere to be more basal in the phylogenetic estimates, but this was not the case.

The two types of mtDNA lineages found in the southern hemisphere are consistent with one, possibly two migrations from the North Atlantic during the Pleistocene. The southern hemisphere D haplotypes are, on average, $1.4 \%$ divergent from the next closest D haplotype from northern hemisphere Mytilus galloprovincialis. Previously estimated rates of sequence evolution in the 16S rRNA gene (Rawson and Hilbish 1995b) suggest a time of divergence between northern and southern hemisphere D clade haplotypes of about 1.2 million years. This is consistent with a migration of mussels from the North Atlantic to the southern hemisphere during the Pleistocene. Shells of Mytilus spp. have been found among late Pleistocene fossil materials in New Zealand, and mainland Australia and Tasmania (Fleming 1959; Hope et al. 1977; Donner and Jungner 1981; Colhoun et al. 1982), supporting a Pleistocene origin of Mytilus spp. in the southern hemisphere.

The remainder of the mtDNA lineages found in the southern hemisphere, with restriction haplotype A, are very closely related to haplotypes found in populations of both Mytilus edulis and M. galloprovincialis in the northern hemisphere. These haplotypes were comparatively rare but were the only mtDNA lineages observed in the five mussels from the Kerguelen Islands. These haplotypes suggest the possibility of a second migration or human transport of Mytilus spp. to the southern hemisphere. Haplotype A is found in both M.edulis and M. galloprovincialis (Rawson and Hilbish 1998) so it is not possible to determine with confidence the origin of this second introduction. The close relationship between the A restriction haplotypes in the northern and southern hemispheres suggests that this introduction is very recent, perhaps even contemporary, but the fact that the southern hemisphere A haplotypes are not identical in sequence to any of those observed in the northern hemisphere indicates that their introduction could predate human activity. Information from faster evolving portions of the mitochondrial genome may clarify the affinity of these haplotypes but with the present data the close relationship of A haplotypes in the two hemispheres precludes any firm conclusions about the timing of this migration.
Alternatively it is possible that all of the haplotypes observed in the southern hemisphere may have arisen from a single migration event. Such a hypothesis would have to account for the discrepancy between the frequency of A haplotypes observed in northern hemisphere populations of Mytilus galloprovincialis ( $>50 \%$ ) and those observed in the southern hemisphere $(<5 \%$, excluding the Kerguelen Islands). Two variants of this hypothesis could reconcile these observations: (1) migration could have occurred recently, and during or following introduction of the A haplotype its frequencies could have drifted to low levels compared to those observed in the northern hemisphere, and (2) migration occurred earlier in the evolutionary history of $\mathrm{M}$. galloprovincialis before asymmetric migration led to high frequencies of A haplotypes within northern hemisphere populations of this species. The first variant of this hypothesis predicts that both the A and D haplotypes observed in the southern hemisphere will be very closely related to or identical with those found in the northern hemisphere. The second variant predicts that the $\mathrm{A}$ and D haplotypes in the southern hemisphere will be equally and appreciably divergent from those found in the northern hemisphere. Neither of these predictions is supported; D haplotypes in the southern hemisphere cluster together and appear to be distinct from those found in the northern hemisphere, whereas southern hemisphere A haplotypes appear to be much more recently derived from northern hemisphere A haplotypes. Overall, these results support the hypothesis of two migration events better than they support one migration event.

McDonald et al. (1991) previously examined allozyme variation among southern and northern hemisphere populations of Mytilus spp. They found evidence for two distinct populations in the southern hemisphere; one group was similar to $M$. galloprovincialis and was found in Australia and New Zealand (i.e. the "Australian group"), while the second group was intermediate in allele frequency between $M$. edulis and M. galloprovincialis and occurred in Castro and Punta Arenas, Chile and the Falkland Islands (i.e. the "South American group"). Both groups, however, contained alleles that were rare or absent in the northern hemisphere. Based on the present data, the two groups, separated on the basis of allozyme frequencies, are dominated by the southern hemisphere D haplotype clade. Furthermore, both allozyme groups contained mtDNA haplotypes that were identical at the sequence level; haplotype SH2 (Fig. 2) occurred at a frequency of $38 \%$ in both the Australian and South American groups.

The nuclear population genetics of the South American group (excluding the Kerguelen Islands) identified by McDonald et al. (1991) is consistent with our mtDNA results. The allozyme frequencies indicate they are intermediate between Mytilus edulis and M. galloprovincialis, and the mtDNA results indicate they are derived from mussels sharing a common ancestor with M. galloprovincialis 1.2 mya. For mussel populations in 
Australia and New Zealand the results of the allozyme analysis of McDonald et al. (1991) are not entirely consistent with the mtDNA data; the mtDNA results indicate an ancient relationship between northern hemisphere M. galloprovincialis and the Australian group, while the allozyme data indicate a much greater similarity. One possible explanation for this difference is that the second migration may have had a greater effect on the composition of the nuclear genome than it did on the mitochondrial genome of the Australian group, and had little effect on either genome of the South American group. Such patterns are not unprecedented, particularly where two taxa can hybridize (Arnold 1997). Many species, including two examples from bivalve mollusks (M. edulis/M. galloprovincialis, Rawson and Hilbish 1998; Quesada et al. 1998; and Mercenaria mercenaria/ M. campechensis, Ó Foighil et al. 1996), exhibit patterns of cyto-nuclear disequilibria that have probably arisen through hybridization (Arnold 1997). If this explanation is correct, it indicates that the second and more recent migration event also originated from northern hemisphere populations of $M$. galloprovincialis since these mussels most resemble the Australian group in their mtDNA sequences.

Mussels from the Kerguelen Islands were distinct from other populations of the southern hemisphere. Mussels from the Kerguelen Islands have previously been described as a distinct species, Mytilus desolationis (Lamy 1936). While we only obtained sequence information from five mussels from the Kerguelen Islands, all of them were A haplotypes. At the allozyme level mussels from the Kerguelen Islands are very similar to the South American group (McDonald et al. 1991). Blot et al. (1988) reported that the composition of the nuclear genomes of mussels in the Kerguelen Islands showed strong evidence of having been subject to genetic drift. Based on RFLP analysis of the whole mitochondrial genome, Blot et al. (1990) also concluded that the mtDNA genomes of mussels from the Kerguelen Islands were distinct from those in mussels from southwest England and south Wales (Edwards and Skibinski 1987). The distinctiveness of the Kerguelen Islands population may be due solely to genetic drift since they are $3500 \mathrm{~km}$ from the nearest continental land mass making it one of the most isolated areas on Earth (Blot et al. 1988) (Fig. 1). More work is required on mussels from the Kerguelen Islands before their taxonomic status and evolutionary history is clear.

In summary we conclude that the mtDNA data support the hypothesis that there have been two introductions of Mytilus spp. from the northern hemisphere into the southern hemisphere. The vast majority of mtDNA lineages found in the southern hemisphere appear to be the result of an ancient migration event that probably occurred in the Pleistocene through the Atlantic. A few mtDNA lineages appear to be the result of a second and more recent migration that also occurred through the Atlantic. There was no evidence that mussels invaded the southern hemisphere via a Pacific route.
Lindberg (1991) concluded that most antitropical distributions of marine species arose through transequatorial migration through the Pacific. Vermeij (1992) further argued that transequatorial migration via routes through the Atlantic was highly unlikely. Phylogenetic analysis of other taxonomic groups exhibiting antitropical distribution patterns could determine whether the route and timing of the transequatorial migrations in Mytilus spp. is atypical or whether the history of formation of antitropical distributions is more heterogeneous that previously thought.

Acknowledgements We would like to thank I. Uriarte, M.H. Gallardo, B. Williams and J.P.A. Gardner for collecting specimens of Mytilus spp. in the southern hemisphere. We acknowledge the support of NSF Grants DEB-8918027 to RKK and AM and OCE9203320 and DEB-9509742 to TJH.

\section{References}

Arnold ML (1997) Natural hybridization and evolution. Oxford University Press, Oxford

Beaumont AR, Seed R, Garcia-Martinez P (1989) Genetic relationships among populations of Mytilus edulis and M. galloprovincialis. In: Ryland J, Tyler PA (eds) Proc 23rd Eur Mar Biol Symp, Swansea, UK. Olsen and Olsen, Fredensborg, Denmark, pp 251-258

Blot M, Legendre B, Albert P (1990) Restriction fragment length polymorphism of mitochondrial DNA in subantarctic mussels. J exp mar Biol Ecol 141: 79-86

Blot M, Thiriot-Quievreux C, Soyer J (1988) Genetic relationships among populations of Mytilus desolationis from Kerguelen, M. edulis from the North Atlantic and M. galloprovincialis from the Mediterranean. Mar Ecol Prog Ser 44: 239-247

Bremmer K (1994) Branch support and tree stability. Cladistics 10: 295-304

Cabot EL, Beckenbach AT (1989) Simultaneous editing of multiple nucleic acid and protein sequences with ESEE. Comput applic Biosci 5: 233-234

Carlton JT (1989) Man's role in changing the face of the ocean biological invasions and implications for conservation of nearshore environments. Conserv Biol 3: 265-273

Carlton JT, Geller JB (1993) Ecological roulette - the global transport of nonindigenous marine organisms. Science 261: 78-82

Colhoun EA, Turner E, van de Geer D (1982) Late Pleitocene marine molluscan faunas from sites in Tasmania. Pap Proc R Soc Tasm 116: 91-96

Devereux J, Haeberli P, Smithies O (1984) A comprehensive set of sequence analysis programs for the VAX. Nucleic Acid Res 12: $387-395$

Donner J, Jungner H (1981) Radiocarbon dating of marine shells from southeastern Australia as a means of dating relative sea-level changes. Ann Acad Sci Fenn Ser A III Geol Geogr 131: 1-44

Edwards CA, Skibinski DOF (1987) Genetic variation of mitochandrial DNA in mussel (Mytilus edulis and M. galloprovincialis) populations from south west England and south Wales. Mar Biol 94: 547-556

Ekman S (1953) Zoogeography of the sea. Sidgwick and Jackson, London

Fleming CA (1959) Notes on New Zealand recent and tertiary mussels (Mytilidae). Trans R Soc NZ 87: 165-178

Gosling EM (1984) The systematic status of Mytilus galloprovincialis in western Europe: a review. Malacologia 25: 551568

Gosling EM (1992) Systematics and geographic distribution of Mytilus. In: Gosling EM (ed) The mussel Mytilus: ecology, 
physiology, genetics and culture. Elsevier, Amsterdam, pp $1-20$

Grant WS, Cherry MI (1985) Mytilus galloprovincialis Lmk. in southern Africa. J exp mar Biol Ecol 90: 179-191

Gyllensten UB, Erlich HA (1988) Generation of single-strandedDNA by the polymerase chain-reaction and its application to direct sequencing of the HLA-DQA locus. Proc natn Acad Sci USA 85: 7652-7656

Hope JR, Lampert RJ, Edmondson E, Smith MJ, van Tets GF (1977) Late Pleistocene faunal remains from Seton rock shelter, Kangaroo Island, South Australia. J Biogeogr 4: 363-385

Hubbs CL (1952) Antitropical distribution of fishes and other organisms. Proc 7th Pacif Sci Congr 3: 324-329

Keigwin LD Jr (1982) Isotopic paleoceanography of the Caribbean and East Pacific: role of Panama uplift in late Neogene time. Science 217: 350-353

Koehn RK (1991) The genetics and taxonomy of species in the genus Mytilus. Aquaculture, Amsterdam 94: 125-145

Lamy E (1936) Revision des mollusques vivants du Museum Nationale del'Historie Naturelle de Paris. J Conch, Paris 80: 66-102

Lindberg DR (1991) Marine biotic interchange between the northern and southern hemispheres. Paleobiology 17: 308-324

McDonald JH, Seed R, Koehn RK (1991) Allozymes and morphometric characters of three species of Mytilus in the northern and southern hemispheres. Mar Biol 111: 323-333

Moore TC Jr, Hutson WH, Kipp N, Hays JD, Prell W, Thompson P, Boden G (1981) The biological record of the ice-age ocean. Palaeogeogr palaeoclim Palaeoecol 35: 203-234

Ó Foighil D, Hilbish TJ, Showman RM (1996) Mitochondrial gene variation in Mercenaria clam sibling species reveals a relict secondary contact zone in the western Gulf of Mexico. Mar Biol 126: 675-683

Palumbi SR, Baker CS (1994) Contrasting population structure from nuclear intron sequences and mtDNA of hump-back whales. Molec Ecol Evolut 11: 426-435
Palumbi S, Martin AP, Roman S, McMillan WO, Stice L, Grabowski G (1991) The simple fool's guide to PCR. Special Publ Dept Zoology, University of Hawaii, Honolulu

Pielou EC (1979) Biogeography. John Wiley and Sons, New York

Quesada H, Gallagher C, Skibinski DAG, Skibinski DOF (1998) Patterns of polymorphism and gene flow of gender-associated mitochondrial DNA lineages in European mussel populations. Molec Ecol 7: 1041-1051

Raven PH (1963) Amphitropical relationships in the floras of North and South America. Q Rev Biol 38: 151-177

Rawson PD, Hilbish TJ (1995a) Distribution of male and female transmitted mitochondrial lineages in the mussels Mytilus trossulus and $M$. galloprovincialis on the west coast of North America. Mar Biol 124: 245-250

Rawson PD, Hilbish TJ (1995b) Evolutionary relationships among the male and female mitochondrial DNA lineages in the Mytilus edulis species complex. Molec Biol Evolut 12: 893-901

Rawson PD, Hilbish TJ (1998) Asymmetric introgression of mitochondrial DNA among European populations of blue mussels (Mytilus spp.). Evolution 52: 100-108

Santelices B (1980) Phytogeographic characterization of the temperate coast of Pacific South America. Phycologia 19: 1-12

Suchanek TH, Geller JB, Kreiser BR, Mitton JB (1997) Zoogeographic distributions of the sibling species Mytilus galloprovincialis and M. trossulus (Bivalvia: Mytilidae) and their hybrids in the North Pacific. Biol Bull mar biol Lab, Woods Hole 193: 187-194

Swofford DL (1998) PAUP*: Phylogenetic Analysis Using Parsimony (*and other methods), Ver. 4. Sinauer Associates, Sunderland, Massachusetts

Vermeij GJ (1991) Anatomy of an invasion: the trans-Arctic interchange. Paleobiology 17: 281-307

Vermeij GJ (1992) Trans-equatorial connections between biotas in the temperate eastern Atlantic. Mar Biol 112: 343-348

Weaver AJ (1990) Ocean currents and climate. Nature 347: p 432 